\title{
Rapid Imaging of Tumor Cell Death In Vivo Using the C2A Domain of Synaptotagmin-I
}

\author{
André A. Neves ${ }^{1}$, Bangwen Xie ${ }^{1}$, Sarah Fawcett ${ }^{1}$, Israt S. Alam ${ }^{1}$, Timothy H. Witney ${ }^{2}$, Maaike M. de Backer ${ }^{2}$, \\ Julia Summers $^{1}$, William Hughes ${ }^{1}$, Sarah McGuire ${ }^{1}$, Dmitry Soloviev ${ }^{1}$, Jodi Miller ${ }^{1}$, William J. Howat ${ }^{1}$, De-en Hu${ }^{1}$, \\ Tiago B. Rodrigues ${ }^{1}$, David Y. Lewis ${ }^{1}$, and Kevin M. Brindle ${ }^{1,2}$ \\ ${ }^{1}$ Cancer Research United Kingdom Cambridge Institute, Li Ka Shing Centre, Cambridge, United Kingdom; and ${ }^{2}$ Department of \\ Biochemistry, University of Cambridge, Cambridge, United Kingdom
}

\begin{abstract}
Cell death is an important target for imaging the early response of tumors to treatment. We describe here the validation of a phosphatidylserine-binding agent for detecting tumor cell death in vivo based on the C2A domain of synaptotagmin-I. Methods: The capability of nearinfrared fluorophore-labeled and ${ }^{99 \mathrm{mTC}}$ - and ${ }^{111} \mathrm{In}$-labeled derivatives of C2Am for imaging tumor cell death, using planar near-infrared fluorescence imaging and SPECT, respectively, was evaluated in implanted and genetically engineered mouse models of lymphoma and in a human colorectal xenograft. Results: The fluorophorelabeled C2Am derivative showed predominantly renal clearance and high specificity and sensitivity for detecting low levels of tumor cell death $(2 \%-5 \%)$. There was a significant correlation $(R>0.9$, $P<0.05)$ between fluorescently labeled C2Am binding and histologic markers of cell death, including cleaved caspase-3, whereas there was no such correlation with a site-directed mutant of C2Am (iC2Am)

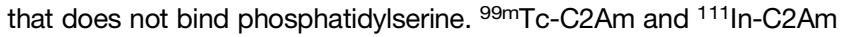
also showed favorable biodistribution profiles, with predominantly renal clearance and low nonspecific retention in the liver and spleen at

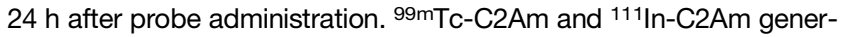
ated tumor-to-muscle ratios in drug-treated tumors of $4.3 \times$ and $2.2 \times$, respectively, at $2 \mathrm{~h}$ and $7.3 \times$ and $4.1 \times$, respectively, at $24 \mathrm{~h}$ after administration. Conclusion: Given the favorable biodistribution profile of ${ }^{99 \mathrm{mTC}}$ - and ${ }^{111} \mathrm{In}$-labeled C2Am, and their ability to produce rapid and cell death-specific image contrast, these agents have potential for clinical translation.
\end{abstract}

Key Words: cell death; C2A; synaptotagmin; imaging; mouse; tumor

J Nucl Med 2017; 58:881-887

DOI: 10.2967/jnumed.116.183004

D etection of the early responses of tumors to therapy would allow rapid selection of the most effective treatment. Currently, clinical assessment of treatment response is based on RECIST, which define partial response as a reduction of at least $30 \%$ in the sum of the diameters of the target lesion (1). The problem for early detection of response is that these morphologic changes may occur only weeks after the start of treatment and fail to detect response to cytostatic therapies (2).

Received Aug. 24, 2016; revision accepted Jan. 17, 2017.

For correspondence or reprints contact: André A. Neves, CRUK Cambridge Institute, Li Ka Shing Centre, Robinson Way, Cambridge CB2 ORE, U.K.

E-mail: andre.neves@cruk.cam.ac.uk

Published online Feb. 16, 2017.

COPYRIGHT (C) 2017 by the Society of Nuclear Medicine and Molecular Imaging.
Cell death is an important target for imaging early treatment response (3), because most treatments induce tumor apoptosis or necrosis. However, there is as yet no reliable technique for routine imaging of cell death in the clinic (4). Phosphatidylserine, which is externalized on the outer leaflet of the plasma membrane bilayer in apoptosis and is exposed through permeabilization of the plasma membrane in necrotic cells, can be detected using the 36-kDa phosphatidylserine-binding protein annexin-V (5). ${ }^{99 \mathrm{~m}}$ Tc-labeled annexin- $\mathrm{V}$ has been used to image drug-induced cell death in human tumors, including breast, lymphoma, lung (6), and head and neck squamous cell carcinoma (7). However, despite early promise, and the development of novel site-directed mutants of annexin- $\mathrm{V}$ with improved biodistribution (8), problems with this agent persisted (9), including suboptimal pharmacokinetics and nonspecific binding (10).

We have developed a phosphatidylserine-targeted agent based on the C2A domain of synaptotagmin-I. This was first used, in animal models, in the form of a dimeric glutathione S-transferase-tagged construct $(84 \mathrm{kDa})$ for imaging tumor cell death using MRI $(11,12)$ as well as in ${ }^{99 \mathrm{~m}} \mathrm{Tc}$-labeled form, for imaging tumor cell death (13) and cardiac ischemia using SPECT (14), and in ${ }^{18} \mathrm{~F}$-labeled form, for imaging cell death in a rabbit lung cancer model using PET (15).

More recently, we have used the isolated C2A domain (16), which is much smaller (16 kDa), giving better tissue access and clearance, in which we have introduced a site-directed mutation (S78C; C2Am) that allows site-specific modification with an imaging label. Studies in vitro demonstrated that this probe showed a 4-fold-lower binding to viable cells and consequently improved specificity for detecting apoptosis and necrosis, when compared with annexin-V (16). Moreover, removal of the glutathione S-transferase tag, which is likely to be immunogenic, should facilitate translation of this agent to the clinic.

We have evaluated here the speed of detection, specificity, sensitivity, and biodistribution profiles of AlexaFluor-750- and ${ }^{99 \mathrm{~m}} \mathrm{Tc}$ - and ${ }^{111} \mathrm{In}$-labeled C2Am, for near-infrared fluorescence and SPECT imaging, respectively, of cell death in implanted models of lymphoma (EL4) (11) and colorectal cancer (Colo205) (17), and in a spontaneous Myc-driven model of Burkitt's lymphoma (E $\mu$-myc) (18). We also describe a site-directed mutant of C2Am (iC2Am, D108N) that is inactive in phosphatidylserine binding, which we used to demonstrate that there were only low levels of nonspecific probe retention.

\section{MATERIALS AND METHODS}

\section{Probe Expression and Chemical Labeling}

$\mathrm{C} 2 \mathrm{Am}$ and $\mathrm{iC} 2 \mathrm{Am}$ were expressed, purified, and labeled using AlexaFluor-750 C5-maleimide, maleimide-hydrazinonicotinamide 


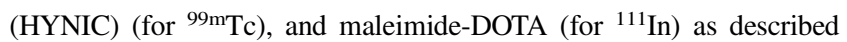
previously (16). Successful conjugation was confirmed using electrospray ionization mass spectrometry and radio-high-performance liquid chromatography (Supplemental Figs. 1 and 2; supplemental materials are available at http://jnm.snmjournals.org). Phosphatidylserine-binding activity of the conjugates was confirmed by surface plasmon resonance measurements (Supplemental Table 1).

\section{Cell Culture}

EL4, murine lymphoma, and Colo-205, human colorectal cells (American Type Culture Collection) were cultured in RPMI medium (Life Technologies) containing $300 \mathrm{mg} / \mathrm{L}$ L-glutamine and 10\% (v/v) fetal bovine serum (PAA Laboratories). Cell death was induced in EL4 cells by treatment with $15 \mu \mathrm{M}$ etoposide (Pharmachemie BV) for $24 \mathrm{~h}$ at $37^{\circ} \mathrm{C}$. An automated analyzer (Vi-Cell; Beckman Coulter) was used to monitor cell number and viability.

\section{Animals and Tumor Models}

EL4 or Colo-205 cells ( $>95 \%$ viability) were washed, resuspended in chilled phosphate-buffered saline, and implanted $(5 \times$ $10^{6}$ cells) subcutaneously under isoflurane anesthesia, in the flank of C57BL/6 (BL6) or between the shoulder blades of BALB/c nude mice (8- to 12-wk-old females, from Charles Rivers Laboratories), respectively. Tumors were allowed to develop for between 8 and 13 d. Animals bearing EL4 tumors were treated with etoposide $(67 \mathrm{mg} / \mathrm{kg}$ of body weight; intraperitoneally) or solvent vehicle, at $24 \mathrm{~h}$ before imaging. BALB/c nude mice bearing Colo-205 tumors were treated with 5-fluorouracil (5-FU; Sigma-Aldrich) $(250 \mathrm{mg} / \mathrm{kg}$ of body weight; intraperitoneally) or solvent vehicle, at $24 \mathrm{~h}$ before imaging. E $\mu$-myc animals (Jackson Laboratories) were monitored daily and enrolled into the study when palpable lymph node masses were detectable (18). The mice were treated with cyclophosphamide (Sigma-Aldrich) $(200 \mathrm{mg} / \mathrm{kg}$ of body weight; intraperitoneally), at 24-48 $\mathrm{h}$ before imaging.

\section{Biodistribution and Near-Infrared Fluorescence Imaging Studies}

C2Am-AF750, iC2Am-AF750, or annexin-V-750 (Annexin-Vivo; Perkin Elmer) was administered at $0.10 \mu \mathrm{mol} / \mathrm{kg}(10 \mathrm{~mL} / \mathrm{kg}$; intravenously) to tumor-bearing BALB/c nude mice. Imaging in vivo or ex vivo was performed using Li-Cor Pearl-Impulse or Xenogen IVIS200 (Perkin Elmer) small-animal imaging systems. Li-Cor Imaging Studio software (version 3.1.4) or Perkin Elmer Living Image (version 3.2) was used for image analysis.

\section{Biodistribution and SPECT Studies}

Twenty-four hours after chemotherapy treatment, tumor-bearing mice received an injection $\left(10 \mathrm{~mL} / \mathrm{kg}\right.$; intravenously) of either ${ }^{99 \mathrm{~m}} \mathrm{Tc}-\mathrm{C} 2 \mathrm{Am}$
(EL4 and E $\mu$-myc models) or ${ }^{111}$ In-C2Am (Colo-205 model) at $7.5 \mathrm{nmol} / \mathrm{kg}(0.12 \mathrm{mg} / \mathrm{kg}$, or $\sim 1.5-2 \mathrm{MBq}$ per mouse). SPECT studies were conducted in separate cohorts of mice $2 \mathrm{~h}$ after administration of radiolabeled $\mathrm{C} 2 \mathrm{Am}$ at $75 \mathrm{nmol} / \mathrm{kg}(1.2 \mathrm{mg} / \mathrm{kg}$ or $\sim 15-20 \mathrm{MBq}$ per mouse; intravenously). Specific activities were $10-11.5 \mathrm{MBq} / \mathrm{hmol}$ for both ${ }^{99 \mathrm{~m}} \mathrm{Tc}$ - and ${ }^{111} \mathrm{In}$-labeled C2Am. Injected doses were determined using a dose calibrator (ISO-MED 2000; MED NuklearMedizintechnik $\mathrm{GmbH}$ ) and corrected for decay.

\section{Study Approval}

All animal experiments were performed in compliance with a project license issued under the Animals (Scientific Procedures) Act of 1986 and were designed with reference to guidelines of the U.K. Coordinating Committee on Cancer Research for the welfare of animals in experimental neoplasia (19). Protocols were approved by the Cancer Research U.K., Cambridge Institute Animal Welfare and Ethical Review Body.

Additional information is available in the supplemental materials.

\section{RESULTS}

\section{Preparation and Characterization of Imaging Probes}

iC2Am-AF750 was produced by site-directed mutagenesis (D108N) of C2Am. This mutation abolishes binding to phosphatidylserine (20). C2Am and iC2Am were prepared and labeled with AlexaFluor-750 (C2Am-AF750, iC2Am-AF750), as described previously (16). The proteins were fully modified, yielding a single molecular species on electrospray ionization mass spectrometry (Supplemental Figs. 1A and 1B). C2AmAF750, C2Am-HYNIC, and C2Am-DOTA bound phosphatidylserine with similar affinities $(\mathrm{Kd}, \sim 60-90 \mathrm{nM}$; Supplemental Table 1), as determined using surface plasmon resonance measurements (16). As expected, iC2Am-AF750 showed no binding. C2Am was also modified stoichiometrically with maleimideHYNIC or maleimide-DOTA, generating a single species of molecular weights $16,426.5$ and $16,749.8 \mathrm{Da}$, respectively, as determined by electrospray ionization mass spectrometry (Supplemental Figs. 1C and 1D). C2Am-HYNIC was loaded with ${ }^{99 \mathrm{~m}} \mathrm{Tc}$ using methods described previously (21). C2Am-DOTA was loaded with ${ }^{111} \mathrm{InCl}_{3}$ as described in the supplemental materials. The conjugates were analyzed by HPLC (Supplemental Fig. 2). Radiolabeling efficiency was greater than $94 \%$.

\section{Fluorescence Imaging of Tumor Cell Death In Vivo}

There was increased retention of C2Am-AF750 in drug-treated as compared with untreated EL4 (Figs. 1A and 2A), Colo-205

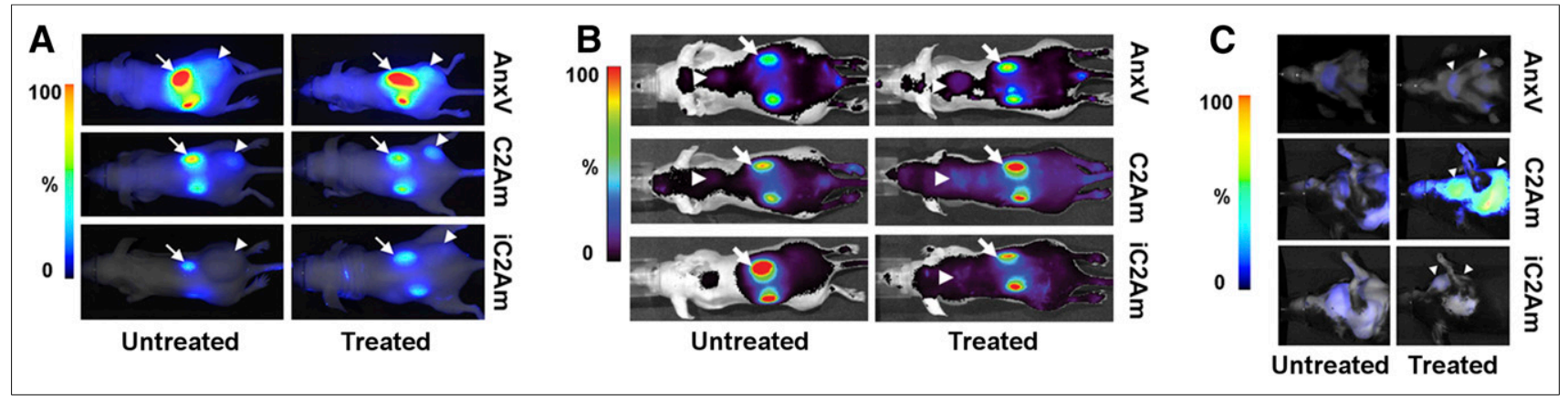

FIGURE 1. Near-infrared fluorescence imaging of cell death. Imaging in vivo of untreated and treated EL4 (A), Colo-205 (B), and E $\mu$-myc (C) tumors. Images are overlays of bright-field images and $800 \mathrm{~nm}$-channel fluorescence signals, acquired $24 \mathrm{~h}$ after C2Am-AF750 administration. AnxV = annexin-V. 


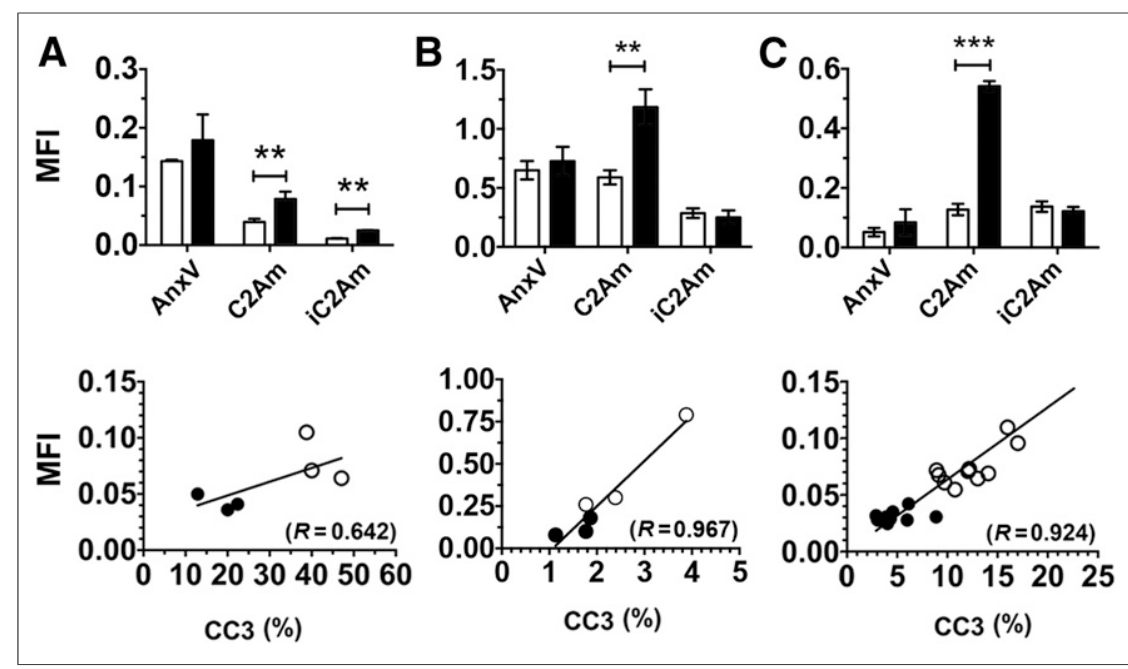

FIGURE 2. Quantification of tumor mean fluorescence intensity (MFI) for untreated (open bars) and

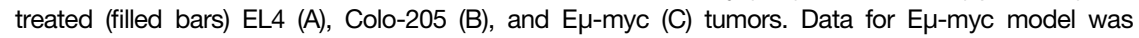
acquired ex vivo, due to skin pigmentation artifacts. (Bottom) Correlation of C2Am whole-tumor MFIs

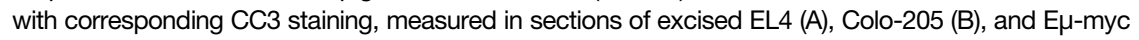
(C) tumors. $\mathrm{O}=$ drug-treated (48 $\mathrm{h}$ after treatment); $\bullet=$ untreated. ${ }^{\star \star} P<0.01,{ }^{{ }^{\star \star}} \mathrm{P}<0.001, n=$ 3/group, values are mean $\pm S D$. AnxV $=$ annexin-V.

(Figs. 1B and 2B), and E $\mu$-myc tumors (Figs. 1C and 2C) at $24 \mathrm{~h}$ after probe injection. Anx-AF750 showed no increase in retention after drug treatment in any of the tumor models. Although Anx-AF750 fluorescence was greater than that of C2Am-AF750 in the EL4 tumor model, this was not increased by drug treatment. The retention of iC2Am-AF750 in drug-treated tumors was less than that of $\mathrm{C} 2 \mathrm{Am}-\mathrm{AF} 750$ in all of the tumor models, and there was no significant difference in the retention of iC2Am-AF750 in untreated or treated Colo-205 (Fig. 2B) and E $\mu$-myc tumors (Fig. 2C). In drug-treated EL4 tumors, there was an increase in tumor fluorescence in animals injected with iC2Am-AF750 (Fig. 2A); however, the levels were 3 times lower than with C2Am-AF750, possibly due to a treatmentinduced increase in the enhanced permeability and retention effect in this tumor model (22). The heterogeneous skin pigmentation of E $\mu$-myc mice prevented accurate optical imaging in vivo, and therefore for this tumor model fluorescence was measured ex vivo (Fig. 2C), which may explain the better contrast observed. All 3 tumor models showed a correlation between whole-tumor mean C2Am-AF750 fluorescence intensities and cleaved and activated caspase-3 (CC3) staining of histologic sections obtained postmortem (Figs. 2A-2C, lower panels). This correlation was confirmed microscopically (Fig. 3). In E $\mu$-myc tumors, C2Am-AF750 fluorescence was detected from regions in which CC3 staining occupied as little as $1 \%-2 \%$ of the approximately $1 \mathrm{~mm}^{2}$ regions of interest (Fig. 3C). Differences in the relationship between fluorescence intensity and the levels of cleaved caspase3 in the different tumors (Fig. 3) may reflect differences in phosphatidylserine exposure.

\section{Cell Binding Experiments with ${ }^{99 m}$ Tc-C2Am}

Because we were unable to detect treatment response with annexin-V-AF750, despite using the most recent agent and according to the manufacturer's instructions, radionuclide imaging studies were performed solely with C2Am labeled with either ${ }^{99 \mathrm{~m}} \mathrm{Tc}$ or ${ }^{111} \mathrm{In}$. There was a significant increase in the radioactivity retained by washed cell pellets prepared from suspensions of EL4 lymphoma cells that had been treated with etoposide $(15 \mu \mathrm{M}$, for $24 \mathrm{~h})$ and then incubated with ${ }^{99 \mathrm{~m}} \mathrm{Tc}-\mathrm{C} 2 \mathrm{Am}$ in the concentration range of 1-100 $\mathrm{nM}$ (Fig. 4A). Cell viability decreased from $95 \%$ to $75 \%$ in these drug-treated cells, as assessed by trypan blue dye exclusion.

\section{Biodistribution}

${ }^{99 m} \mathrm{Tc}-\mathrm{C} 2 \mathrm{Am}$ and ${ }^{111} \mathrm{In}-\mathrm{C} 2 \mathrm{Am}$ showed favorable biodistribution profiles, with predominantly renal clearance (Table 1). ${ }^{99 \mathrm{~m}} \mathrm{Tc}-\mathrm{C} 2 \mathrm{Am}$ had blood half-lives in EL4 tumor-bearing animals of $7.2 \pm 0.6$ and $9.7 \pm 0.1 \mathrm{~h}$ in etoposide-treated and untreated animals, respectively. ${ }^{111} \mathrm{In}-\mathrm{C} 2 \mathrm{Am}$ showed similar half-lives in Colo-205 tumor-bearing animals of $11.4 \pm 1.2$ and $8.0 \pm 0.8 \mathrm{~h}$ in 5 -FU-treated and untreated animals, respectively. Tumor-to-blood ratios increased progressively in chemotherapy-treated EL4 tumor-bearing animals, from $1.71 \pm 0.40$ at $2 \mathrm{~h}$ to $6.96 \pm 1.08$ at $24 \mathrm{~h}$ for ${ }^{99 \mathrm{~m}} \mathrm{Tc}-\mathrm{C} 2 \mathrm{Am}$ and from $1.38 \pm 0.65$ at $2 \mathrm{~h}$ to $5.43 \pm 0.96$ at $24 \mathrm{~h}$ for ${ }^{111} \mathrm{In}-$ C2Am in Colo-205 tumor-bearing animals. There was significantly greater retention in tumors and spleens (Fig. 4B, $P<$ $0.05)$ from etoposide-treated EL4 tumor-bearing animals, from as early as $2 \mathrm{~h}$ after drug administration. The spleens showed significant increases in the levels of cell death after drug treatment (Supplemental Fig. 3).

The biodistribution profiles of C2Am-AF750 and iC2Am-AF750 (Supplemental Table 2) were similar to those of ${ }^{99 \mathrm{~m}} \mathrm{Tc}-\mathrm{C} 2 \mathrm{Am}$ and
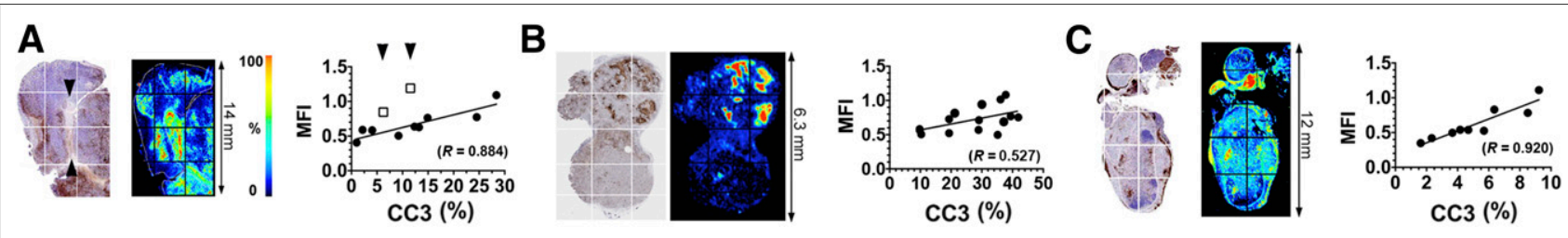

FIGURE 3. Maps of CC3 staining (left), C2Am-AF750 fluorescence (middle), and correlation (right) of fluorescence intensities of regions of interest (grids indicated on the left), with staining for $\mathrm{CC} 3$ in same regions of interest. Tumors were excised $24 \mathrm{~h}$ after $\mathrm{C} 2 \mathrm{Am}-\mathrm{AF} 750$ administration and $48 \mathrm{~h}$ after drug treatment. The correlation coefficients $(R)$ of the linear fits to the data (A-C, right) are shown. Arrows in $A$ (left) indicate decellularized regions of tissue. Sections are from EL4 (A), Colo-205 (B), and E H-myc (C) tumors. MFI = mean fluorescence intensity. 


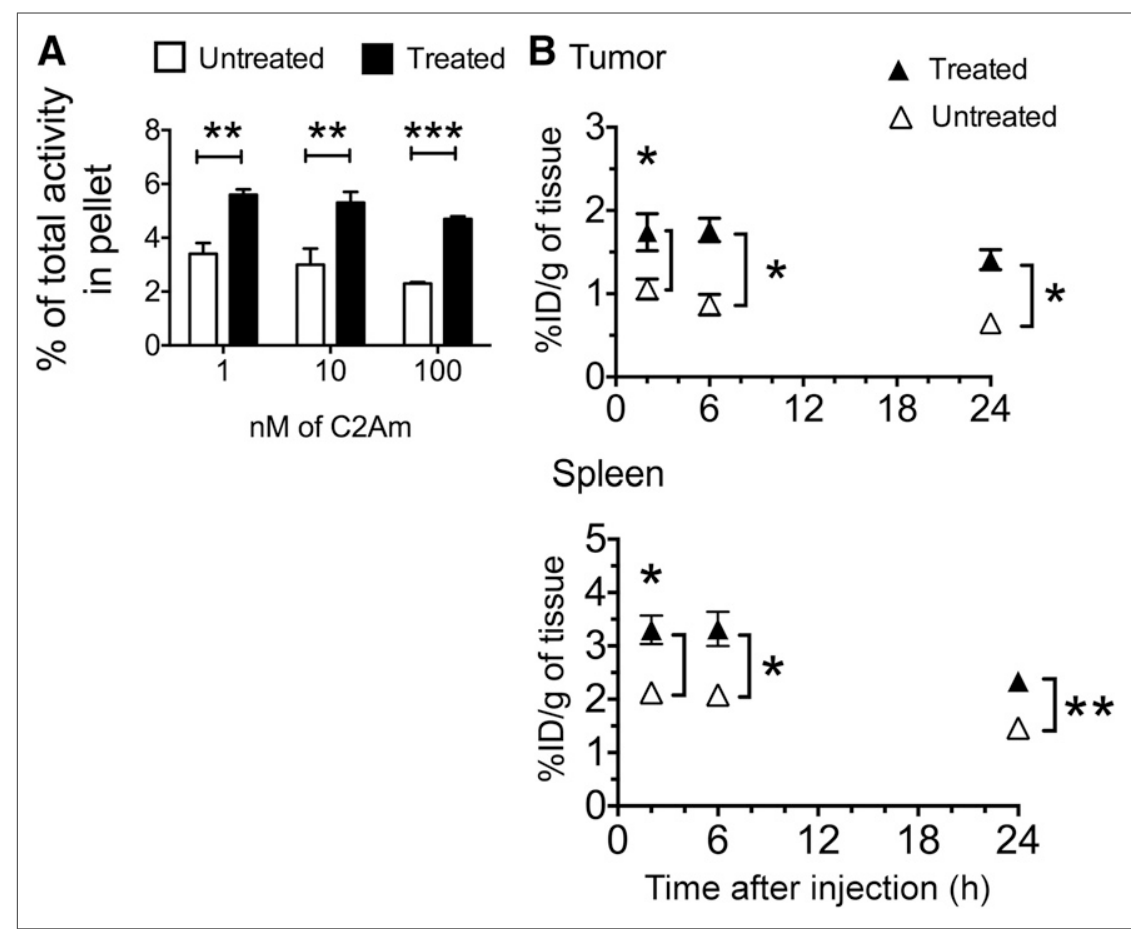

FIGURE 4. (A) Binding of ${ }^{99 m T C-C 2 A m}$ to EL4 cells. Labeling of drug-treated and untreated cells is expressed as percentage of total ${ }^{99 \mathrm{~m} T c}$ activity retained by cell pellets. ${ }^{* \star} P<0.01$, ${ }^{* \star \star} P<0.001, n=3$ /group, values are mean \pm SD. (B) Retention of ${ }^{99 m T C}-C 2 A m$ in tumors (top) and spleens (bottom) from EL4 tumor-bearing mice, in untreated $(\triangle)$ and drug-treated $(\boldsymbol{\Delta})$ animals, at indicated times after probe administration. Tissue retention is expressed as percentage injected dose per gram (\%ID/g) of tissue. ${ }^{*} P<0.05,{ }^{* \star} P<0.01, n=3 /$ group, 2-way ANOVA, with Bonferroni posttest correction, was used for group comparisons. Values are mean \pm SD.

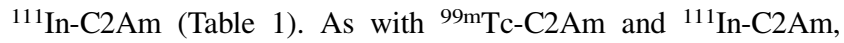
C2Am-AF750 generated EL4 tumor-to-muscle contrast from as early as $2 \mathrm{~h}(2.2 \pm 0.49)$ and up to $24 \mathrm{~h}(3.63 \pm 0.4)$ after injection of the imaging agent (Supplemental Table 2).

\section{SPECT Imaging of Tumor Cell Death In Vivo Using ${ }^{99 m}$ Tc-C2Am and ${ }^{111}$ In-C2Am}

Images were acquired from animals with implanted Colo-205 (Fig. 5A) tumors and from tumor-bearing E $\mu$-myc mice (Fig. $6 \mathrm{~A}$ ) before and $24 \mathrm{~h}$ after treatment with 5-FU or cyclophosphamide, respectively, and $2 \mathrm{~h}$ after injection of ${ }^{111} \mathrm{In}-\mathrm{C} 2 \mathrm{Am}$ or ${ }^{99 \mathrm{~m}} \mathrm{Tc}-\mathrm{C} 2 \mathrm{Am}$, respectively. Corresponding studies with ${ }^{99 \mathrm{~m}} \mathrm{Tc}-$ C2Am in etoposide-treated EL4 tumors are shown in Supplemental Figure 4. Maximum activity was observed in the kidneys and bladder, consistent with a predominantly renal excretion route (Table 1). Renal retention was mostly cortical (Supplemental Fig. 4A). In 5-FU-treated Colo-205 tumors (Fig. 5), ${ }^{111}$ InC2Am uptake was increased by approximately 1.6 times (Fig. 5B, upper panel, $P<0.05)$, reflecting a similar increase $(1.65 \times)$ in the percentage of dead cells determined histologically in tumor sections (Fig. 5B, lower panel, $P<0.05$ ). In $\mathrm{E} \mu$-myc mice, ${ }^{99 m} \mathrm{Tc}-\mathrm{C} 2 \mathrm{Am}$ detected baseline levels of cell death in cervical tumors (Fig. 6A, left), and there was an approximately 1.9 times increase $(P<0.0001)$ in tumor signal after treatment (Fig. 6B, upper panel). Both cervical (Fig. 6A, 1) and axillary (Fig. 6A, 2) node tumors were clearly visible (Fig. 6A, arrowheads) after treatment (Supplemental Video 1). Histologic analysis of tumor sections showed a similar increase in tumor cell death after treatment $(\sim 3 \times$;
$P<0.05$ ) (Fig. 6B, lower panel). In EL4 tumors ${ }^{99 \mathrm{~m}} \mathrm{Tc}-\mathrm{C} 2 \mathrm{Am}$ uptake increased after treatment by approximately 1.3 times $(P<0.05)$, paralleling the modest increase and reflecting the wide variation in the levels of cell death in this tumor model $(\sim 1.6 \times ; P<0.05)$. Treatment response was also observed in the spleen and salivary glands of these etoposidetreated animals (Supplemental Fig. 4; Supplemental Video 1).

\section{DISCUSSION}

Phosphatidylserine exposed by dying cells constitutes a temporally stable and abundant biomarker for detection of cell death (23). We have been developing the C2Am domain of synaptotagmin-I, which binds phosphatidylserine with nanomolar affinity, as a cell death imaging agent (16). Previous work with mouse lymphoma (EL4) and human triplenegative breast cancer (MDA-MB-231) cells demonstrated that $\mathrm{C} 2 \mathrm{Am}$ has a higher specificity for binding to dead and dying cells in vitro, when compared with annexin-V (16). We have demonstrated here, in vivo, that ${ }^{99 \mathrm{~m}} \mathrm{Tc}-\mathrm{C} 2 \mathrm{Am}$ and ${ }^{111}$ In-C2Am have favorable biodistribution profiles, with predominantly renal clearance (Table 1; Supplemental Fig. 4), and that $\mathrm{C} 2 \mathrm{Am}$ was capable of detecting cell death in vivo with high sensitivity and specificity, in 3 mouse models, from as early as $2 \mathrm{~h}$ after administration.

The binding of C2Am-AF750 was closely correlated with tumor cell death (Figs. 1-3), detecting cell death in regions with levels of $\mathrm{CC} 3$ staining as low as approximately $2 \%$ (Fig. 2B, lower panel; Figs. $3 \mathrm{~A}$ and $3 \mathrm{C}$, right panels). Although iC2Am-AF750 showed a small increase in uptake in EL4 tumors after treatment (Fig. 2A, upper panel), this likely reflects an increased enhanced permeability and retention effect after treatment (24). This effect was not observed in the other 2 tumor models, E $\mu$-myc and Colo-205 (Figs. 2B and 2C, upper panels), possibly due to lower levels of cell death in these models leading to better clearance of the probe from the tumor.

${ }^{111} \mathrm{In}-\mathrm{C} 2 \mathrm{Am}$ detected a treatment response in Colo-205 tumors within $2 \mathrm{~h}$ of probe administration, where the $60 \%$ increase in probe retention in treated tumors paralleled the increase in cell death determined histologically in tumor sections obtained postmortem, from $1.59 \% \pm 0.17 \%$ to $2.62 \% \pm 0.48 \%$ (Fig. $5 \mathrm{~B}, P<0.05$ ). In $\mathrm{E} \mu$-myc tumors, treatment resulted in a greater proportional increase in cell death $(3 \times)$ and consequently a greater increase in 99m Tc-C2Am retention (1.9×) (Fig. 6). In EL4 tumors, despite high levels of preexisting cell death and a modest increase after treatment (1.6×) (Supplemental Fig. 4B), ${ }^{99 \mathrm{~m} T c-C 2 A m}$ was nevertheless able to detect a significant treatment response $(1.3 \times$ increase in probe retention, $P<0.05$, Supplemental Fig. 4B). The capability of C2Am to detect small percentage increases in cell death suggests that $\mathrm{C} 2 \mathrm{Am}$ should be capable of detecting treatment response in the clinic. For example, levels of cell death can range from less than $2 \%$ 
TABLE 1

Biodistribution of $99 \mathrm{mTc}-\mathrm{C} 2 \mathrm{Am}$ in Tumor-Bearing EL4 Mice and ${ }^{111} \mathrm{In}-\mathrm{C} 2 \mathrm{Am}$ in Tumor-Bearing Colo-205 Mice, 24 Hours After Etoposide and 5-FU Treatment, Respectively

\begin{tabular}{|c|c|c|c|c|}
\hline \multirow[b]{2}{*}{ Tissue $(\% \mathrm{ID} / \mathrm{g})$} & \multicolumn{2}{|c|}{$2 \mathrm{~h}$} & \multicolumn{2}{|c|}{$24 \mathrm{~h}$} \\
\hline & Mean & SD & Mean & SD \\
\hline \multicolumn{5}{|l|}{ Tumor-bearing EL4 mice } \\
\hline Muscle & 0.39 & 0.05 & 0.19 & 0.02 \\
\hline Blood & 1.02 & 0.08 & 0.20 & 0.01 \\
\hline Tumor & 1.74 & 0.39 & 1.41 & 0.21 \\
\hline Spleen & 3.30 & 0.47 & 2.34 & 0.29 \\
\hline Liver & 6.17 & 0.98 & 5.14 & 0.90 \\
\hline Kidney & 194.2 & 45.9 & 157.4 & 57.0 \\
\hline Tumor-to-blood & 1.71 & 0.40 & 6.96 & 1.08 \\
\hline Tumor-to-muscle & 4.5 & 1.15 & 7.3 & 1.40 \\
\hline \multicolumn{5}{|c|}{ Tumor-bearing Colo-205 mice } \\
\hline Muscle & 0.32 & 0.07 & 0.18 & 0.02 \\
\hline Blood & 0.50 & 0.22 & 0.13 & 0.02 \\
\hline Tumor & 0.69 & 0.09 & 0.72 & 0.10 \\
\hline Spleen & 0.92 & 0.17 & 1.18 & 0.20 \\
\hline Liver & 2.01 & 0.34 & 2.17 & 0.53 \\
\hline Kidney & 310 & 12 & 275 & 22 \\
\hline Tumor-to-blood & 1.38 & 0.65 & 5.43 & 0.96 \\
\hline Tumor-to-muscle & 2.16 & 0.48 & 4.09 & 0.88 \\
\hline
\end{tabular}

$\% \mathrm{ID} / \mathrm{g}=$ percentage injected dose per gram

$n=3 /$ group.

before treatment to $5 \%-15 \%$ after treatment (25). These data also suggest that $\mathrm{C} 2 \mathrm{Am}$ would be effective clinically in those tumors that show high levels of preexisting cell death, such as non-Hodgkin lymphoma, in which high levels of spontaneous cell death (necrosis) have been reported in $25 \%$ of patients, frequently correlating with advanced disease and poor prognosis (26). Increased uptake of ${ }^{99 \mathrm{~m}} \mathrm{Tc}-\mathrm{C} 2 \mathrm{Am}$ was also observed in the spleen and salivary glands of etoposide-treated animals (Fig. 4B; Supplemental Fig. 4A) and can be explained by etoposide-induced cell death in these tissues $(27,28)$.

Several imaging agents have been developed to detect tumor cell death, some of which have progressed to the clinic. Annexin-V binds phosphatidylserine with high affinity (5) and has been used widely as a preclinical tool for detecting cell death, both in vitro and in vivo. However, binding of annexin- $\mathrm{V}$ to tumor tissue after therapy is thought not to be entirely phosphatidylserine-specific, possibly explaining the limited success of annexin- $\mathrm{V}$ in the clinic, which has been hampered by high levels of nonspecific binding to viable tissues, including the liver, gut, and kidneys (29). Modifications to annexin- $\mathrm{V}$ have shown limited improvements in biodistribution or contrast agent performance in vivo (8). Duramycin is a 19-amino-acid peptide that binds with high affinity and specificity to the phosphatidylethanolamine externalized by dying cells $(30) .{ }^{99 \mathrm{~m}} \mathrm{Tc}$-labeled duramycin has been used recently to detect response to chemotherapy in a mouse model of colorectal

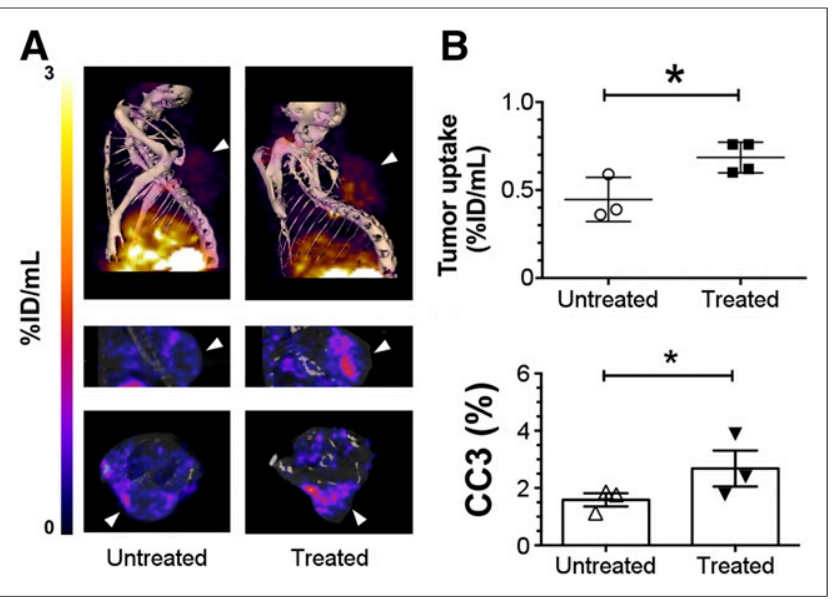

FIGURE 5. SPECT imaging of cell death in vivo in Colo-205 tumors. Imaging of ${ }^{111} \mathrm{In}$-labeled C2Am was performed $2 \mathrm{~h}$ after probe administration and $24 \mathrm{~h}$ after drug treatment. (A) SPECT/CT fusion images of representative untreated Colo-205 tumor-bearing mouse (A, left) and 5-FU-treated animal (A, right), $2 \mathrm{~h}$ after administration of ${ }^{111} \mathrm{In}-\mathrm{C} 2 \mathrm{Am}$. Tumor location is indicated by arrowheads. (B) Tumor retention (percentage injected dose [\% ID]/mL) (upper) and CC3 staining (lower) in untreated and 5-FU-treated tumors. ${ }^{*} P<0.05, n=3-4$ tumors/group.

cancer, in which accumulation of the agent was found to correlate with markers of cell death (31). However, the clinical utility of duramycin has yet to be demonstrated. Imaging agents that target $\mathrm{CC} 3$, an executioner caspase in the apoptosis pathway, have also

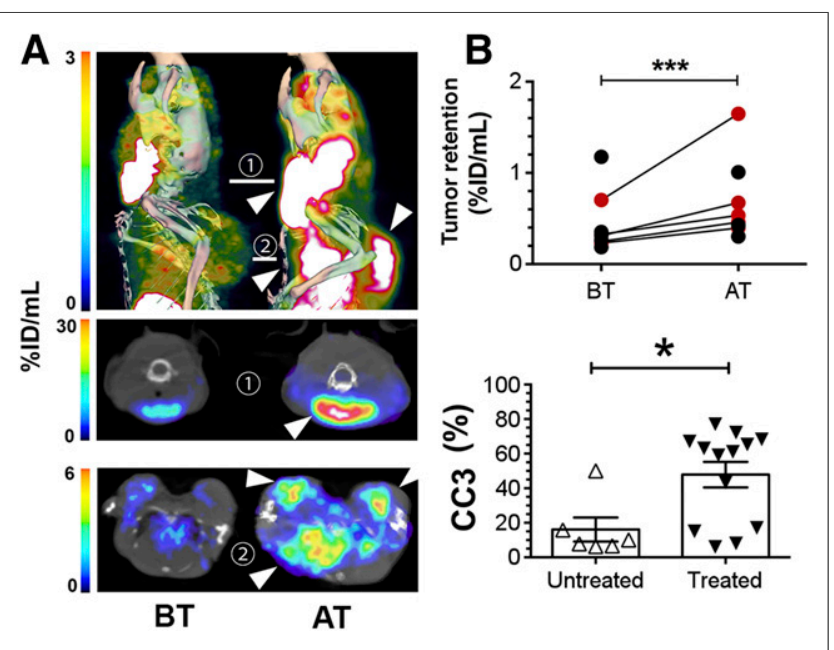

FIGURE 6. SPECT imaging of cell death in vivo in Eu-myc tumors. Imaging of ${ }^{99 m T c-l a b e l e d ~ C 2 A m ~ w a s ~ p e r f o r m e d ~} 2 \mathrm{~h}$ after probe administration, and $24 \mathrm{~h}$ after drug treatment. (A) SPECT/CT fusion images of representative $\mathrm{E} \mu$-myc mice before (left) and after (right) cyclophosphamide treatment. Tumors in neck, axillary region, and chest cavity were visible (arrowheads, top) and in axial sections across cervical (1, middle) and axillary (2, bottom) planes. Red circles in B correspond to percentage injected dose $[\% \mid \mathrm{ID}] / \mathrm{mL}$ retention values for tumors of animals shown in $\mathrm{A}$. CC3 staining $\left(B\right.$, bottom) in untreated and drug-treated tumors. ${ }^{*} P<0.05$, ${ }^{\star \star \star} P<0.0001, n=6-7$ tumors/group (A); $n=6-13$ tumors/group (B). AT $=$ after treatment; BT $=$ before treatment. Supplemental materials provide statistical analysis. Three-dimensional rendering of SPECT data are shown in Supplemental Video 1. 
been developed for detection of cell death in vivo (25), and a probe capable of detecting CC3 has progressed to clinical trials (32). However, because CC3 is a transient biomarker of cell death, the choice of temporal imaging window after treatment is critical (33). Furthermore, CC3-targeted imaging agents are unable to identify caspase-independent modes of cell death, such as necrosis (34), which is often present after chemotherapy or radiotherapy. ${ }^{18} \mathrm{~F}-\mathrm{ML}-10$, which appears to bind to dead cells by an unknown mechanism, has shown favorable safety and biodistribution profiles in humans (35). In a clinical study in 10 patients with brain metastasis, there was enhanced retention (up to 2-fold) of ${ }^{18}$ F-ML-10 after radiotherapy and a good correlation between probe uptake and tumor size reduction (36). However, there was no histologic demonstration of increased cell death and the average reported decrease in tumor size after therapy was substantial ( $\sim 60 \%$ reduction). Therefore, the utility of ${ }^{18} \mathrm{~F}$ ML-10 for detecting cell death in the most common clinical scenarios, in which therapy induces low levels of tumor cell death, has yet to be demonstrated.

\section{CONCLUSION}

We have demonstrated the capability of C2Am to detect tumor cell death in vivo as early as $2 \mathrm{~h}$ after administration. Radiolabeled C2Am derivatives showed favorable biodistribution profiles, with predominantly renal clearance, and there was a close correlation between $\mathrm{C} 2 \mathrm{Am}$ binding and histologic markers of cell death. The capability of $\mathrm{C} 2 \mathrm{Am}$ to detect relatively modest increases in cell death suggests that these agents will have sufficient sensitivity to detect tumor cell death in the clinic.

\section{DISCLOSURE}

This work was supported by a Cancer Research U.K. programme grant to Kevin M. Brindle (17242) and by the CRUK-EPSRC Imaging Centre in Cambridge and Manchester (16465). Sarah Fawcett was the recipient of a $\mathrm{PhD}$ studentship from the Cambridge Biomedical Research Centre of the National Institute of Health Research with financial support from GlaxoSmithKline U.K. Tiago B. Rodrigues received Intra-European Marie Curie (FP7-PEOPLE-2009-IEF, Imaging Lymphoma) and Longterm EMBO (EMBO-ALT-1145-2009) fellowships. C2Am is under a licensing agreement with Cambridge Enterprise, and has been patented (US2011/0038798). Some of the authors of this study (André A. Neves, Israt S. Alam, Maaike M. de Backer, and Kevin M. Brindle) are coinventors on this patent. No other potential conflict of interest relevant to this article was reported.

\section{ACKNOWLEDGMENTS}

We thank Peter Sharat and Len Packman at the Protein and Nucleic Acid Facility (PNAC) of the Department of Biochemistry, University of Cambridge, and Chandra Solanki and Kishor Solanki, of the Nuclear Medicine Department of Addenbrooke's Hospital Cambridge, for their advice and support as well as Sarah Dawson for data analysis. We are grateful to the CRUK Cambridge Institute Histopathology, Research Instrumentation, Imaging, Bioresources, Bioinformatics Core Units, for their support. We thank Li-Cor Inc. for the lease of a Pearl Impulse small-animal imaging system and Jane Gray for her support in the use of a Li-Cor Odyssey scanner. We are grateful to Sandra Fulton for her guidance on site-directed mutagenesis.

\section{REFERENCES}

1. Eisenhauer EA, Therasse P, Bogaerts J, et al. New response evaluation criteria in solid tumours: revised RECIST guideline (version 1.1). Eur J Cancer. 2009;45: 228-247.

2. Brindle K. New approaches for imaging tumour responses to treatment. Nat Rev Cancer. 2008;8:94-107.

3. Neves AA, Brindle KM. Imaging cell death. J Nucl Med. 2014;55:1-4.

4. Dean E, Greystoke A, Ranson M, Dive C. Biomarkers of cell death applicable to early clinical trials. Exp Cell Res. 2012;318:1252-1259.

5. Kuge Y, Zhao S, Takei T, Tamaki N. Molecular imaging of apoptosis with radiolabeled annexin A5 focused on the evaluation of tumor response to chemotherapy. Anticancer Agents Med Chem. 2009;9:1003-1011.

6. Belhocine T, Steinmetz N, Hustinx R, et al. Increased uptake of the apoptosisimaging agent ${ }^{99 \mathrm{~m}} \mathrm{Tc}$ recombinant human annexin $\mathrm{V}$ in human tumors after one course of chemotherapy as a predictor of tumor response and patient prognosis. Clin Cancer Res. 2002;8:2766-2774.

7. Hoebers FJ, Kartachova M, de Bois J, et al. ${ }^{99 \mathrm{~m}}$ Tc Hynic-rh-annexin V scintigraphy for in vivo imaging of apoptosis in patients with head and neck cancer treated with chemoradiotherapy. Eur J Nucl Med Mol Imaging. 2008;35:509518.

8. Bauwens M, De Saint-Hubert M, Devos E, et al. Site-specific ${ }^{68} \mathrm{Ga}$-labeled annexin A5 as a PET imaging agent for apoptosis. Nucl Med Biol. 2011;38:381-392.

9. Kartachova MS, Verheij M, van Eck BL, Hoefnagel CA, Olmos RA. Radionuclide imaging of apoptosis in malignancies: promise and pitfalls of Tc-Hynic-rh-annexin V imaging. Clin Med Oncol. 2008;2:319-325.

10. De Saint-Hubert M, Mottaghy FM, Vunckx K, et al. Site-specific labeling of 'second generation' annexin $\mathrm{V}$ with ${ }^{99 \mathrm{~m}} \mathrm{Tc}(\mathrm{CO}) 3$ for improved imaging of apoptosis in vivo. Bioorg Med Chem. 2010;18:1356-1363.

11. Zhao M, Beauregard DA, Loizou L, Davletov B, Brindle KM. Non-invasive detection of apoptosis using magnetic resonance imaging and a targeted contrast agent. Nat Med. 2001;7:1241-1244.

12. Krishnan AS, Neves AA, de Backer MM, et al. Detection of cell death in tumors by using MR imaging and a gadolinium-based targeted contrast agent. Radiology. 2008;246:854-862.

13. Wang F, Fang W, Zhao M, et al. Imaging paclitaxel (chemotherapy)-induced tumor apoptosis with ${ }^{99 \mathrm{~m}} \mathrm{Tc} \mathrm{C} 2 \mathrm{~A}$, a domain of synaptotagmin I: a preliminary study. Nucl Med Biol. 2008;35:359-364.

14. Fang W, Wang F, Ji S, et al. SPECT imaging of myocardial infarction using ${ }^{99 \mathrm{~m}} \mathrm{Tc}$-labeled C2A domain of synaptotagmin I in a porcine ischemia-reperfusion model. Nucl Med Biol. 2007;34:917-923.

15. Wang F, Fang W, Zhang MR, et al. Evaluation of chemotherapy response in VX2 rabbit lung cancer with ${ }^{18} \mathrm{~F}$-labeled C2A domain of synaptotagmin I. J Nucl Med. 2011;52:592-599.

16. Alam IS, Neves AA, Witney TH, Boren J, Brindle KM. Comparison of the C2A domain of synaptotagmin-I and annexin- $\mathrm{V}$ as probes for detecting cell death. Bioconjug Chem. 2010;21:884-891.

17. Davies BR, Logie A, McKay JS, et al. AZD6244 (ARRY-142886), a potent inhibitor of mitogen-activated protein kinase/extracellular signal-regulated kinase kinase 1/2 kinases: mechanism of action in vivo, pharmacokinetic/pharmacodynamic relationship, and potential for combination in preclinical models. Mol Cancer Ther. 2007;6:2209-2219.

18. Harris AW, Pinkert CA, Crawford M, Langdon WY, Brinster RL, Adams JM. The E mu-myc transgenic mouse: a model for high-incidence spontaneous lymphoma and leukemia of early B cells. J Exp Med. 1988;167:353-371.

19. Workman P, Aboagye EO, Balkwill F, et al. Guidelines for the welfare and use of animals in cancer research. Br J Cancer. 2010;102:1555-1577.

20. von Poser C, Ichtchenko K, Shao X, Rizo J, Sudhof TC. The evolutionary pressure to inactivate: a subclass of synaptotagmins with an amino acid substitution that abolishes Ca2+ binding. J Biol Chem. 1997;272:1431414319.

21. Blankenberg FG, Vanderheyden J-L, Strauss HW, Tait JF. Radiolabeling of HYNICannexin V with technetium-99m for in vivo imaging of apoptosis. Nat Protoc. 2006;1:108-110.

22. Maeda H, Nakamura H, Fang J. The EPR effect for macromolecular drug delivery to solid tumors: improvement of tumor uptake, lowering of systemic toxicity, and distinct tumor imaging in vivo. Adv Drug Deliv Rev. 2013;65:71-79. 
23. Martin SJ, Reutelingsperger CP, McGahon AJ, et al. Early redistribution of plasma membrane phosphatidylserine is a general feature of apoptosis regardless of the initiating stimulus: inhibition by overexpression of Bcl-2 and Abl. $J$ Exp Med. 1995;182:1545-1556.

24. Maeda H, Wu J, Sawa T, Matsumura Y, Hori K. Tumor vascular permeability and the EPR effect in macromolecular therapeutics: a review. J Control Release. 2000;65:271-284.

25. Nguyen QD, Smith G, Glaser M, Perumal M, Arstad E, Aboagye EO. Positron emission tomography imaging of drug-induced tumor apoptosis with a caspase-3/7 specific [ $\left.{ }^{18} \mathrm{~F}\right]-$ labeled isatin sulfonamide. Proc Natl Acad Sci USA. 2009;106: $16375-16380$.

26. Saito A, Takashima S, Takayama F, Kawakami S, Momose M, Matsushita T. Spontaneous extensive necrosis in non-Hodgkin lymphoma: prevalence and clinical significance. J Comput Assist Tomogr. 2001;25:482-486.

27. Sefc L, Psenak O, Sykora V, Sulc K, Necas E. Response of hematopoiesis to cyclophosphamide follows highly specific patterns in bone marrow and spleen. $J$ Hematother Stem Cell Res. 2003;12:47-61.

28. Anderson SM, Reyland ME, Hunter S, Deisher LM, Barzen KA, Quissell DO. Etoposide-induced activation of c-jun N-terminal kinase (JNK) correlates with drug-induced apoptosis in salivary gland acinar cells. Cell Death Differ. 1999;6:454-462.
29. Kurihara H, Yang DJ, Cristofanilli M, et al. Imaging and dosimetry of ${ }^{99 \mathrm{~m}} \mathrm{Tc}$ EC annexin V: preliminary clinical study targeting apoptosis in breast tumors. Appl Radiat Isot. 2008;66:1175-1182.

30. Zhao M. Lantibiotics as probes for phosphatidylethanolamine. Amino Acids. 2011;41:1071-1079.

31. Elvas F, Vangestel C, Rapic S, et al. Characterization of [ $\left.{ }^{99 \mathrm{~m}} \mathrm{Tc}\right]$ duramycin as a SPECT imaging agent for early assessment of tumor apoptosis. Mol Imaging Biol. 2015;17:838-847.

32. Challapalli A, Kenny LM, Hallett WA, et al. ${ }^{18}$ F-ICMT-11, a caspase-3-specific PET tracer for apoptosis: biodistribution and radiation dosimetry. $\mathrm{J} \mathrm{Nucl} \mathrm{Med}$. 2013;54:1551-1556.

33. Reshef A, Shirvan A, Akselrod-Ballin A, Wall A, Ziv I. Small-molecule biomarkers for clinical PET imaging of apoptosis. J Nucl Med. 2010;51:837-840.

34. Witney TH, Fortt RR, Aboagye EO. Preclinical assessment of carboplatin treatment efficacy in lung cancer by ${ }^{18} \mathrm{~F}-\mathrm{ICMT}-11$-positron emission tomography. PLoS One. 2014;9:e91694.

35. Höglund J, Shirvan A, Antoni G, et al. F-18-ML-10, a PET tracer for apoptosis: first human study. J Nucl Med. 2011;52:720-725.

36. Allen AM, Ben-Ami M, Reshef A, et al. Assessment of response of brain metastases to radiotherapy by PET imaging of apoptosis with ${ }^{18} \mathrm{~F}-\mathrm{ML}-10$. Eur $J$ Nucl Med Mol Imaging. 2012;39:1400-1408. 